Isabel González Díaz

Universidad de La Laguna, Tenerife, España

\title{
Mujeres que 'interrumpen' procesos: las primeras antologias feministas em los Estúdios Culturales
}

Resumen: El objeto de este artículo es analizar el proceso de elaboración y producción de las dos primeras antologías editadas por mujeres en la disciplina académica conocida como Estudios Culturales, extrayendo toda la información que ambas publicaciones aportan sobre el papel jugado por las mujeres en la evolución de dicha disciplina. Tras una breve exposición sobre la historia de los Estudios Culturales, así como de los nuevos planteamientos que aportó al mundo académico, entraremos en un apartado que analizará el posterior nacimiento de los Estudios de la Mujer y su relación con los Estudios Culturales. Finalmente, me centraré en el análisis de los procesos de publicación de ambas antologías, que fueron fruto de la incorporación del colectivo feminista a la disciplina. El análisis pretende demostrar que lo que algunos críticos han calificado como 'interrupción', por parte del feminismo, del proceso que seguían los Estudios Culturales a finales de la década de los 70 del siglo XX supuso en realidad una gran aportación a la disciplina. Eso lo demuestra la inclusión de nuevos temas y conceptos en el debate académico, así como de nuevas herramientas de análisis, a pesar de las dificultades a las que se tuvieron que enfrentar las intelectuales feministas en los primeros momentos.

Palabras clave: feminismo; Estudios Culturales; Estudios de la Mujer; antologías.

Copyright () 2009 by Revista Estudos Feministas.

' El término empleado en lengua inglesa para referirse a ese retroceso del feminismo es "backlash", que da título al libro publicado por Susan Faludi en 1992 (Londres: Chatto and Windus). Faludi analizaba las relaciones de género en los Estados Unidos contemporáneos, y planteaba que esa idea del retroceso del feminismo surgió en la década de los 80 del siglo XX,
A estas alturas del siglo XXI a nadie le sorprende encontrar publicaciones en las que, bajo el gran epígrafe de Estudios Culturales, se analizan cuestiones de género y sexualidad. Ese tipo de análisis lleva ya un largo camino recorrido, hasta el punto de que el propio término "feminismo" llega a cuestionarse como algo del pasado, y los críticos hablan de retroceso' del feminismo, de postfeminismo, de la masculinidad y su presunta crisis, o de teoría "queer". En su libro Gender, Culture and Society: Contemporary Femininities and Masculinities, publicado en 2007, Máirtin Mac an Ghaill y Chris Haywood plantean que las cuestiones de género ya han dejado de ser "el coto vedado de una 
extendiéndose principalmente por los medios de comunicación en un intento de hacer perder fuerza a las demandas del feminismo.

2 MAC AN GHAILL y HAYWOOD, 2007, p. 4.

3 MAC AN GHAILL y HAYWOOD, 2007, p. 8-9. minoría política de activistas políticos, como las feministas y los hombres que defienden el feminismo", y el lenguaje sobre el género se utiliza cada vez más "como el eje central desde el que hombres y mujeres articulan su comprensión de ser sujetos en y objetos de un mundo que fluye". ${ }^{2}$ En este libro, que analiza las relaciones de género contemporáneas en el contexto de la sociología y los estudios culturales, Mac an Ghaill y Haywood resaltan la importancia, por un lado, de las primeras teorías feministas, al haber aportado a las ciencias sociales un lenguaje con el que poder entender lo que ellos denominan la "desigualdad estructurada" y por otro, y más recientemente, de las contribuciones del postestructuralismo, el postcolonialismo y la teoría "queer" para entender el género desde perspectivas diferentes, más alejadas de nociones patriarcales. Las relaciones de género son, para estos autores, un punto de intersección en el que confluyen diferentes formas de poder, estratificación, deseo y formación subjetiva de la identidad, y ellos apuestan por la necesidad de mantener la tensión productiva que se produce entre las diferentes explicaciones sociológicas y de estudios culturales que existen acerca de las relaciones de género. ${ }^{3}$

Sin embargo, a pesar de todo lo que se ha avanzado a nivel teórico, quienes se detienen a estudiar los esfuerzos que el feminismo ha tenido que llevar a cabo para abrirse paso dentro de las diferentes disciplinas de estudio que se fueron afianzando en la Academia a lo largo del siglo XX saben que el proceso de aceptación de los análisis de género no fue precisamente un camino fácil. Las pioneras que insistieron en la importancia de incluir esos análisis en el campo de los Estudios Culturales parecían estar luchando contra corriente y, como veremos en estas páginas, su lucha no estuvo exenta de problemas. Fruto de su perseverancia es la naturalidad con la que actualmente se acepta que no es posible entender una sociedad y su cultura, los cambios sociales que se van produciendo, sin analizar las relaciones de género que se establecen dentro de la misma. Esa es sin duda una de las grandes aportaciones del feminismo a los Estudios Culturales, y en este ensayo nos proponemos detenernos a analizar el momento histórico en el que este movimiento comenzó a hacerse oír en esa disciplina. Pero antes de adentrarnos en nuestro análisis, y para contextualizar esa incorporación del feminismo, haremos un repaso a los orígenes de los Estudios Culturales.

\section{Breve historia de los Estudios Culturales}

La disciplina académica que conocemos por el término de 'Estudios Culturales' debe su nombre al Centre 
4 NELSON, TREICHLER Y GROSSBERG, 1992, p. 2. NOTAACLARATORIA: Al no disponer de copias en castellano de los libros citados, la autora ha traducido las diferentes citas que aparecen en el texto, por lo que asumirá cualquier posible error o confusión.

5 NELSON, TREICHLER Y GROSSBERG, 1992, p. 2.

${ }^{6}$ MCROBBIE, 1992, p. 722. for Contemporary Cultural Studies, que fue fundado por Richard Hoggart en la universidad británica de Birmingham en el año 1964. Aunque desde el año 1958, con la publicación de los libros de Raymond Williams, Culture and Society, y Richard Hoggart, The Uses of Literacy ya se puede hablar de los comienzos del tipo de estudio que vino a denominarse 'estudios culturales', fue a lo largo de la década de los setenta del siglo XX, mientras dirigía el Centro Stuart Hall (1969-1979), cuando la disciplina se fue haciendo fuerte, ocupando un cada vez más importante lugar en la Academia. Una de las grandes aportaciones del centro de Birmingham al mundo académico fue su gran interés por incluir los productos de la llamada 'cultura popular' como objeto de análisis, demostrando que pueden ser tan válidos como los productos de la cultura más canónica, tradicionalmente asociada con la élite - la que en inglés se denomina 'high culture'. Otra gran aportación es su enfoque interdisciplinar, que abre puertas a multitud de análisis y reflexiones provenientes desde campos como la sociología, la teoría literaria, 'film/video studies' o la antropología cultural. Pero, como indican Cary Nelson, Paula A. Treichler y Lawrence Grossberg en la introducción a la antología Cultural Studies, de la que son editores, al tiempo que los Estudios Culturales pueden ser definidos como una disciplina interdisciplinar, también se puede decir que tiene un carácter "activa y agresivamente anti disciplinar". ${ }^{4}$ Los editores de Cultural Studies hacen referencia a las palabras de Graeme Turner, quien ha afirmado que sería su feroz crítica a otras disciplinas lo que hace que los Estudios Culturales se muestren reacios a convertirse en una de ellas. ${ }^{5}$ Angela McRobbie, por su parte, plantea cómo los estudios culturales se han convertido en un terreno de estudio controvertido frente a otras disciplinas al tiempo que se resiste a la puridad disciplinaria. ${ }^{6}$

El interés de esta ¿disciplina? se centra en los fenómenos culturales originados en las sociedades industriales, y son conceptos como 'ideología', 'raza', 'clase social' o 'género' los que con más frecuencia han sido revisados por sus estudiosos, en un afán de entender los significados y las prácticas de la vida cotidiana, la producción cultural de los pueblos. Uno de los aspectos más relevantes de ese intencionado carácter anti disciplinar es la ausencia de una metodología de estudio clara, definida y cerrada en el seno de los Estudios Culturales. Si por algo se define la metodología empleada por los numerosos estudiosos de este campo es por su carácter ecléctico y abierto. Simon During, en la antología The Cultural Studies Reader, que editó en 1993, se plantea qué tipo de análisis es el que se realiza desde los Estudios Culturales 
${ }^{7}$ DURING, 1993, p. 1-2.

${ }^{8}$ DURING, 1993, p. 20.

9 WILLIAMS, 1982, p. 295. Ver también NELSON, TREICHLER y GROSSBERG, 1992, p. 4.

10 NELSON, TREICHLER Y GROSSBERG, 1992, p. 8. (sociológico, económico, crítico, ...) y concluye que qunque no es fácil hallar la respuesta, sí que se pueden encontrar dos elementos que caracterizaron a los análisis que se realizaban desde los comienzos de la disciplina en la década de los 50 del siglo XX:

1. Su énfasis en la "subjetividad", es decir, en el estudio de la cultura en relación con las vidas individuales.

2. El tipo de análisis comprometido, que les llevaba a tener en cuenta las desigualdades sociales a la hora de enfrentarse a cualquier clase de estudio. ${ }^{7}$

En opinión de During, la disciplina cambia constantemente tanto sus intereses de estudio como sus métodos debido a su constante y comprometida interacción con el contexto histórico en el que se encuentra ubicada y también porque no puede permitirse el lujo de asentarse en su autoridad académica. ${ }^{8}$

Pero antes de continuar con este discurso se hace necesario parar a reflexionar sobre la definición del término 'cultura', algo que ha hecho derramar litros de tinta en la literatura académica (Raymond Williams, Jody Berland, Paul Willis, John Fiske, Stuart Hall), convirtiéndose en un paso obligado para cualquier estudioso de este campo. Raymond Williams, uno de los autores más influyentes de la disciplina, reflexionaba ya en 1958 sobre el término 'cultura', que invocaría simultáneamente a los campos simbólicos y materiales, y cuyo estudio no debería privilegiar a uno de los dos campos sobre el otro, sino más bien preguntarse por la relación existente entre ambos. ${ }^{9}$ Así pues, en los Estudios Culturales se entiende que la cultura es un término amplio que incluye, como ya hemos comentado, tanto a la cultura popular como a la 'high culture'. Si en un principio desde los Estudios Culturales se entendía la cultura tan sólo como algo material (una obra de arte, una canción o una serie televisiva), a medida que fue avanzando la disciplina, y con las aportaciones de sus estudiosos, surgió lo que se ha dado en llamar el 'giro cultural' (cultural turn), que consistió en un cambio de énfasis hacia el estudio de los procesos de producción de significados. De esta manera, los Estudios Culturales van más allá del análisis del contenido de la producción cultural material, en un afán por describir los procesos discursivos mediante los cuales se forma y se da significado tanto a los objetos como a las identidades. Esto se hace, por ejemplo, en estudios sobre la cultura de la clase trabajadora, sobre las llamadas 'subculturas' juveniles, sobre el papel de los medios de comunicación para producir consenso social, o sobre la relación de los conceptos de clase social y género con la cultura popular. ${ }^{10}$

Todas estas disquisiciones nos conducen a plantearnos otra de las cuestiones de obligada reflexión 
11 NELSON, TREICHLER Y GROSSBERG, 1992, p. 13.
12 NELSON, TREICHLER Y GROSSBERG, 1992, p. 9. dentro - y fuera - del mundo de los Estudios Culturales: el canon. Las preguntas son numerosas: ¿quién lo decide?, ¿quién tiene el poder de decidir? Y, como plantean Nelson, Treichler y Grossberg, iexiste algún producto cultural tan poderoso como para que deba ser suprimido del canon? En última instancia, respondiendo a sus preguntas, ellos mismos afirman que no sólo debe ser examinado el contenido de la selección - quién acaba formando parte del canon, del programa, de la conferencia o del libro, sino también la constitución y las consecuencias de la selección, ya se haya llevado a cabo por poderes progresistas o conservadores. También, en opinión de estos editores, es una obligación de la disciplina interrogar constantemente su propia conexión con las relaciones de poder que le rodean, sus intereses propios. ${ }^{11}$

Desde los comienzos del desarrollo de los Estudios Culturales se observaba una marcada diferencia entre el enfoque que se daba en el Reino Unido y el que se daba en los Estados Unidos, diferencia no exenta de polémica. En su versión británica, identificados con el Centre for Contemporary Cultural Studies, autores como Raymond Williams o Paul Gilroy se posicionaban abiertamente en el ámbito político de la izquierda, haciendo una dura crítica a la cultura de masas capitalista - crítica que bebía de la que la Escuela de Frankfurt hacía de la 'industria de la cultura'. Mientras tanto, los estudiosos americanos, como John Guillory, se centraban en el estudio de las audiencias de esa cultura de masas, analizando sus reacciones, así como los usos que hacían de la cultura. Según afirman Nelson, Treichler y Grossberg en la introducción al libro del que son editores, los académicos americanos se enfrascaban en sus estudios, enmarcándolos dentro de los Estudios Culturales, ignorando por completo el trabajo de los autores más significados de la disciplina, aquellos que "adoptaron, construyeron y formalizaron el término estudios culturales para que diera nombre a su proyecto original y único". ${ }^{12}$

En una versión de la historia de los Estudios Culturales que podríamos calificar de generalista o neutral, o para ser más explícita, que no se centra en una perspectiva de género, los editores de la antología Cultural Studies planteaban en 1992 cómo a lo largo de la década de los 70 del siglo XX, y a comienzos de los 80 , el trabajo realizado por los miembros del Centro de Birmingham fue culminando en la publicación de varias obras sobre la teoría de la subcultura y sobre los medios de comunicación. Poco a poco, con el renovado interés de muchos de sus miembros en la obra de Gramsci y su énfasis en cómo se articulan y se crean los significados, comenzaron a plantearse cuestiones 
13 NELSON, TREICHLER $Y$ GROSSBERG, 1992, p. 9.
${ }^{14}$ WOMEN'S STUDIES GROUP, 1978 , p. 11.

${ }^{15}$ WOMEN'S STUDIES GROUP, 1978, p. 11. como el racismo, la hegemonía y el Thatcherismo. Y es en ese contexto, según los editores de la antología, cuando el feminismo, en forma del Women's Studies Group formado en 1978, "interrumpió" (las comillas son suyas) el desarrollo de aquel proceso obligando a los Estudios Culturales a replantearse nociones tales como subjetividad, política, género y deseo. ${ }^{13}$

\section{La voz de las mujeres en los Estudios Culturales}

En el primer artículo de la primera antología publicada sobre mujeres y Estudios Culturales, Women Take Issue: Aspects of Women's Subordination (1978), del que hablaremos extensamente en el siguiente apartado de esta presentación, el grupo de editoras dedica algunas páginas a hacer una breve historia de los orígenes del Women's Studies Group en el Centro de Estudios Culturales Contemporáneos de la Universidad de Birmingham. Como quiera que esta pequeña historia local resume muchos de los debates y relaciones intelectuales que se produjeron tras la aparición del feminismo en el mundo académico, nos detendremos en analizar las dificultades con que se encontraron las mujeres del grupo de Birmingham, así como sus logros.

El grupo se constituyó en el año 1974, y hasta esa fecha - recordemos que desde 1964 - sólo dos ó tres mujeres habían formado parte del Centro de Estudios Culturales, frente a unos veinte hombres. Ellas habían trabajado en varios de los subgrupos que se habían formado en el Centro, pero en ninguno de esos equipos de trabajo observaban un interés por las mujeres como objeto de estudio. Según afirman las editoras de la antología, se encontraban en una situación de aislamiento al tiempo que interrogaban los textos teóricos y académicos que discutían con sus compañeros, encontrando una importante ausencia estructural de las mujeres en la mayor parte de los mismos. ${ }^{14}$ Su interés se centró, por tanto, en intentar entender la experiencia de la ausencia de las mujeres a nivel teórico para analizar cómo el género estructura y es a su vez estructurado. Las editoras de la antología confiesan que en aquella etapa les resultaba extremadamente difícil participar en las actividades del Centro, y sentían, sin ser capaces de articularlo, que era un caso de dominación masculina tanto del trabajo intelectual como del entorno en el que éste se llevaba a cabo. ${ }^{15}$

Fue gracias al apoyo del Women Liberation Movement y a la llegada en 1974 de más mujeres que se interesaban por trabajar sobre mujeres como finalmente se 
${ }^{16}$ WOMEN'S STUDIES GROUP, 1978, p. 12.

${ }^{17}$ WOMEN'S STUDIES GROUP, 1978, p. 12. organizaron para crear el Women's Studies Group, que inicialmente estaba abierto a la participación tanto de hombres como de mujeres; el primer hombre que se unió al grupo lo hizo en el segundo semestre del año 1975. Pero las editoras de Women Take Issue relatan el estatus ambiguo del grupo de estudios de la mujer dentro del Centro, debido a que éste cumplía una función de apoyo mutuo entre sus miembros, similar a la de los grupos de concienciación del movimiento de liberación de las mujeres. Eso generó problemas tanto en términos del trabajo que realizaban como de la manera en que lo llevaban a cabo. El dilema era el siguiente: como mujeres, inevitablemente ellas eran el sujeto y el objeto de su propio estudio, y eso generaba una tensión que por una parte les proporcionaba el impulso político para realizar su trabajo y por otra les proporcionaba un tipo de humor, una manera de trabajar y un entendimiento de las incertidumbres que iban encontrando en su quehacer como mujeres; y todo ello basado en el reconocimiento de sus experiencias comunes de feminidad. ${ }^{16}$ Las implicaciones de todas estas consideraciones resultaron en una división entre ellas por la cuestión de si el grupo debía ser explícitamente cerrado - es decir, si excluían a los hombres, como ocurría en los grupos del movimiento de liberación de las mujeres. Todas esas disquisiciones, como ellas mismas reconocen, no hacían más que lanzar mensajes contradictorios al resto de miembros del Centro de Birmingham. Así, con la intención de resolver el dilema, propusieron en junio de 1976 crear un forum de mujeres, es decir, un grupo cerrado exclusivamente para mujeres, al que se invitaba a participar a todas las mujeres que formaban parte del Centro. De esa manera, el grupo de estudios de la mujer podía continuar con su proyecto intelectual incluyendo a los compañeros que estuvieran interesados en esos estudios al tiempo que las discusiones sobre temas feministas más generales tenían lugar en el forum. La propuesta, según cuentan las editoras, provocó largos debates en una reunión en la que en principio nadie pareció oponerse: "Ahora veríamos esto en muchas maneras como los comienzos de un debate más abierto sobre las implicaciones del feminismo para el Centro de Estudios Culturales Contemporáneos en su conjunto". ${ }^{17}$

Uno de los primeros proyectos que ocupó al grupo de estudios de mujeres en 1974 fue el de examinar las imágenes de las mujeres en los medios de comunicación. Ese trabajo, según relatan en la introducción a Women Take Issue, les ayudó a entender las complejidades que subyacen en torno a la feminidad bajo el simple uso del sustantivo 'mujer', pero también les hizo reflexionar como grupo sobre las dificultades del trabajo colectivo y sobre el problema 
${ }^{18}$ WOMEN'S STUDIES GROUP, 1978 , p. 12-13.

${ }^{19}$ WOMEN'S STUDIES GROUP, 1978, p. 13.

${ }^{20}$ WOMEN'S STUDIES GROUP, 1978, p. 13. del tipo de lector al que se dirigían sus escritos. En 1978 reconocían que este último dilema aún les acompañaba, y había sido motivo de amplios debates a la hora de publicar esa primera antología sobre mujeres y Estudios Culturales; en consecuencia ese trabajo sobre las imágenes de las mujeres en los medios fue haciéndose cada vez más teórico. ${ }^{18}$ Tras ese proyecto, el siguiente que emprendieron entraba de lleno en el debate sobre el trabajo doméstico, en un intento de considerar la relación existente entre clase social y subordinación de las mujeres a nivel teórico. Las imágenes de la mujer que arrojaban los medios de comunicación eran tanto la de mujer como objeto sexual como las de mujer como madre y ama de casa, y esas últimas provocaron que en el grupo tomaran la decisión de intentar desarrollar un análisis marxista-feminista de la subordinación de las mujeres. ${ }^{19}$ El problema al que se tuvieron que enfrentar en aquel momento fue el de articular las relaciones de los conceptos de sexo y género con el de clase, así como el de determinar la importancia que esos conceptos tenían en la lucha política. De hecho, según reconocen las editoras de esta antología, los análisis sobre el trabajo que se habían llevado a cabo desde el marxismo 'ortodoxo' excluían constantemente las especificidades de sexo y género, por lo que ellas se veían en la obligación de incorporar esos conceptos al debate teórico existente. ${ }^{20}$

A pesar de que las diferencias intelectuales y políticas dentro del grupo fueron en aumento, tanto por discrepancias internas, como por discrepancias con el Centro de Estudios Culturales en su conjunto, y de que todos los hombres y algunas de las mujeres que pertenecían al mismo lo abandonaron, se mantuvo un grupo de mujeres que se esforzó por encontrar un terreno común desde el que trabajar. Se centraron principalmente en la idea de la subordinación de las mujeres a nivel económico, recurriendo a textos feministas de principios de la década de los 70 del siglo XX, como los de Rowbotham y Mitchell. Ese nivel de compromiso teórico les permitía además, en opinión de las editoras de la antología, mantenerse conectadas a otros trabajos que se estaban llevando a cabo en el Centro, lo cual quedó claro cuando 'presentaron' sus resultados ante todos sus miembros a finales del año 1977. Fue en ese período cuando comenzaron a hablar de la posibilidad de publicar la antología, y sus editoras afirman lo siguiente: "Lo que finalmente provocó que el CCCS nos permitiera hacer este libro no fue solamente que hubiésemos 'demostrado' nuestras capacidades en cuanto a nuestro trabajo teórico en los análisis económicos en nuestra presentación ...; también lo provocó el hecho de que escucharan las grabaciones de mujeres que hablaban de sus vidas como amas de casa, 
${ }^{21}$ WOMEN'S STUDIES GROUP, 1978 , p. 14-15. una poderosa demostración de la opresión de las mujeres, y del objetivo político de nuestro trabajo intelectual". ${ }^{21}$

\section{Antologías de Estudios Culturales sobre mujeres y género}

\subsection{Women Take Issue: Aspects of Women's Subordination}

En 1978, el Women's Studies Group perteneciente al Centre for Contemporary Cultural Studies de Birmingham editó la que sería la primera antología de Estudios Culturales centrada exclusivamente en los estudios de la mujer, titulado Women Take Issue: Aspects of Women's Subordination. El libro no presenta a ninguno de los miembros de su grupo editorial como editor principal, limitándose a ofrecer el listado de editoras en la primera página, y explicando en el primer ensayo que ha sido producido por un colectivo de investigadoras e investigadores del Women's Studies Group (nueve mujeres y dos hombres). En su portada aparece una ilustración en la cual se observa la parte delantera de una lavadora de ojo de buey detrás de cuyo cristal se pueden ver dos mujeres trabajadoras de una fábrica, una más joven, la otra en una edad más madura, ambas con el mismo uniforme y con la mirada fija en la cinta mecánica realizando exactamente el mismo trabajo. La marca de la lavadora, que aparece en la parte superior derecha de la misma es 'Freedomatic' (una clara ironía, pues combina las palabras 'libre' y 'hogar'). La ilustración resume perfectamente los dos ámbitos en que se mueven las mujeres de la clase trabajadora, así como el tipo de trabajo monótono y sumiso que deben realizar.

Los nueve ensayos recogidos en la antología no se presentan estructurados bajo ningún epígrafe, pero según aparece en la contraportada del libro, éste se encuentra dividido en dos partes. En la primera encontramos un artículo retrospectivo sobre la historia del Women's Studies Group que aparece firmado por todo el grupo editorial, y en el que dan cuenta de los problemas encontrados al intentar llevar a cabo un trabajo intelectual feminista; a ese artículo le sigue otro que analiza algunos de los aspectos que ocuparon a las primeras intelectuales del movimiento feminista, como la naturaleza de las mujeres o la dicotomía entre lo personal y lo político; el tercer y último artículo de esta parte de la antología se acerca a la base económica de la opresión de las mujeres, analizando la relación entre mujeres y relaciones de producción. La segunda parte del libro incluye artículos que tratan desde la opresión de las amas de casa a la cultura de la feminidad de las adolescentes de la clase 
22 WOMEN'S STUDIES GROUP, 1978 , p. 7.

${ }^{23}$ WOMEN'S STUDIES GROUP, 1978 , p. 7. trabajadora, pasando por otros en los que se analiza la aportación del psicoanálisis a la sexualidad y subjetividad o el reflejo de la ideología de la feminidad en una revista de mujeres titulada Woman, para cerrar con dos artículos sobre las relaciones de reproducción, uno desde el punto de vista de la antropología y otro que analiza la relación entre las relaciones de reproducción y la ideología del romance. Cuatro de los nueve ensayos de esta antología son colectivos.

Nos vamos a detener nuevamente en el primero de ellos, pues ofrece información muy valiosa tanto sobre la historia del grupo de Estudios de la Mujer, como pudimos ver en el apartado anterior, como sobre sus objetivos principales al publicar la antología. Como ya hemos dicho, el ensayo está firmado por todo el grupo editorial, y lleva por título "Women's Studies Group: Trying to Do Feminist Intellectual Work". En la introducción las autoras presentan la actividad del Centre for Contemporary Cultural Studies, indicando que en el mismo no sólo se realizan investigaciones individuales sino también trabajos colectivos sobre temas de interés común para algunos de sus miembros, como la educación, los medios de comunicación o los estudios de la mujer. Explican que desde que el Centro se fundara, cada año se presenta la memoria ante el Departamento, y de esa memoria surge la base de los temas principales que aparecen publicados en la revista anual del Centro, Working Papers in Cultural Studies.

El grupo editorial de Women Take Issue afirma que cuando se tomó la decisión de hacer el libro lo que realmente pensaban era que estaban produciendo el número decimoprimero de la revista, algo que ya tocaba si se tiene en cuenta que en los diez números anteriores tan sólo habían aparecido cuatro artículos relacionados con los estudios de la mujer. ${ }^{22}$ Sin embargo, y tal como aparece explicado en la contraportada del libro, tras la elaboración de este volumen el Centro tomó la decisión de reemplazar la revista Working Papers in Cultural Studies por una colección anual cuyo primer volumen es el de esta antología que se convertiría en la primera antología de mujeres publicada en la disciplina de Estudios Culturales. Esa 'invisibilidad' de las mujeres en la revista y en buena parte del trabajo intelectual del Centro a la que hacen referencia las editoras de Women Take Issue es resultado, según ellas, de un número complejo de factores que van detallando a lo largo del ensayo, y que en su opinión puede explicar tanto la historia de la antología que presentan como los problemas más generales de los estudios de la mujer y de los intentos de llevar a cabo un trabajo intelectual desde una perspectiva feminista. ${ }^{23}$ 
${ }^{24}$ WOMEN'S STUDIES GROUP, 1978 , p. 7.

${ }^{25}$ WOMEN'S STUDIES GROUP, 1978 , p. 8.

${ }^{26}$ WOMEN'S STUDIES GROUP, 1978, p. 8 .
Las editoras comienzan afirmando que el objetivo de su trabajo se centra en cuestionar muchas de las nociones existentes en la sociedad acerca del papel y de la construcción del sexo y el género, así como en analizar de qué forma esas nociones se adquieren y se transmiten, añadiendo: "A través de las preguntas que formula el feminismo, y de las ausencias que detecta se va constituyendo la investigación feminista y los estudios de la mujer como uno de los aspectos de la lucha por transformar la sociedad con el fin último de que los 'estudios de la mujer' lleguen a ser algo innecesario". ${ }^{24}$ Ese objetivo político ubicado dentro de un contexto académico presentaba, como ellas mismas afirman, problemas entre la práctica intelectual y la política, provocando ambigüedades y distintos grados de compromiso entre los miembros del colectivo. Las discusiones sobre el tema llevaron a las integrantes del Grupo de Estudios de la Mujer a plantearse a quién debían dirigir su producción intelectual, cuestionándose si debían asumir que sus lectores serían marxistas o feministas, ambas cosas a la vez, o ninguna. También hicieron un esfuerzo por intentar ser conscientes del uso de los conceptos teóricos que manejaban para entender la subordinación de las mujeres con mayor precisión, frente a la tendencia general dentro del Centro a no ser conscientes del lenguaje teórico que empleaban, que en opinión de las editoras de Women Take Issue es uno de los elementos que contribuye a perpetuar el conocimiento como propiedad de unos pocos. El relato de estos aspectos de su quehacer académico concluye afirmando que no creen haber tenido éxito en distinguir esos usos que hacían del lenguaje. ${ }^{25}$

Esa 'debilidad' que afirman forma parte de su proceso colectivo no es la única que las editoras de la antología comparten con sus lectores; de hecho, admiten que los estudios de la mujer como campo académico debe asumir algunas contradicciones, entre otras la de concentrarse en sus propias experiencias como grupo dentro de la institución académica, algo que no ocurre porque consideren que ese énfasis en la experiencia compartida sea más importante, sino debido a la necesidad de trabajar colectivamente tanto para llegar a tener un conocimiento profundo de las mismas como para interrogarse y apropiarse del 'conocimiento' y las prácticas que excluyen o ignoran a las mujeres. ${ }^{26}$ En 1978, cuando esta antología fue publicada, la dicotomía entre lo académico y lo no académico formaba parte del debate principal para definir qué era exactamente lo que se entendía por Estudios de la Mujer. En opinión de las editoras, el hecho de que el campo de estudio fuera tan amplio podía ser asumido como algo positivo, dada la considerable diversidad en objetivos, métodos y contenidos 
${ }^{27}$ WOMEN'S STUDIES GROUP, 1978, p. 8-9.

${ }^{28}$ WOMEN'S STUDIES GROUP, 1978, p. 9.

${ }^{29}$ WOMEN'S STUDIES GROUP, 1978, p. 9-10. que aportaba a la disciplina. Y eso sin olvidar el carácter potencialmente subversivo de las prácticas no académicas, con su rechazo a las estructuras de aprendizaje en un intento de reemplazarlas por otras que se pudieran convertir en una alternativa al conocimiento generado en las instituciones. Los orígenes eminentemente políticos de la disciplina, que surgía de la conciencia de la subordinación y explotación económica, ideológica, sexual y política de las mujeres como grupo social hacían necesario que ésta se presentara de diferentes formas, y que su propia aparición dentro del contexto académico fuera tanto el resultado como la razón de conflictos dentro y fuera de ese contexto. ${ }^{27}$

En el cuestionamiento constante que se hacían como grupo sobre qué querían que fueran los estudios de la mujer, las intelectuales del Centro de Birmingham se hacían preguntas como las siguientes: "iqueremos despertar conciencias, aportar argumentos, cambiar el sistema educativo, producir feministas? ¿Todas esas cosas juntas? ¿O acaso ninguna de ellas?". ${ }^{28}$ De esas preguntas, las editoras de Women Take Issue sacan cuatro conclusiones que comparten con sus lectores, y en las que merece la pena detenernos: ${ }^{29}$

1. El hecho de que una persona opte por sumarse a los Estudios de la Mujer puede en buena parte despertar su conciencia, ya que son principalmente las mujeres las que se acercan a este tipo de estudios. Los cursos en los que se matriculen y las lecturas que hagan les pueden proporcionar material de reflexión sobre sus experiencias personales, de tal manera que puedan ubicarlas dentro de un contexto sociológico e histórico más amplio.

2. El punto de partida de los cursos sobre los estudios de la mujer es diferente del de otras disciplinas, centrándose en las mujeres como eje central, desplazando así su esfera de actividades desde los márgenes hasta el centro. Eso puede provocar el descubrimiento de nuevo material empírico o el cambio de perspectiva que se puede realizar sobre material ya existente.

3. Los estudios de la mujer hacen una crítica del sexismo y el machismo en las teorías, textos y cursos que circulan por la academia, lo cual hace necesario la formulación de una teoría que explique cómo ocurren los procesos de subordinación estructural de las mujeres.

4. Esto a su vez conduce a la necesidad de desarrollar herramientas conceptuales para llevar a cabo un análisis feminista. Como ejemplo dan, entre otros, la posibilidad de comenzar a separar los conceptos de 'sexo' y 'género', citando a Ann Oakley (Sex, Gender and Society, 1972), y también sugieren la creación de nuevos conceptos con significados específicos. 
${ }^{30}$ WOMEN'S STUDIES GROUP, 1978, p. 10.

${ }^{31}$ WOMEN'S STUDIES GROUP, 1978, p. 11.

${ }^{32}$ WOMEN'S STUDIES GROUP, 1978, p. 15.
Entre las mayores dificultades intelectuales y políticas a las que se tuvieron que enfrentar para llevar a cabo el trabajo desde las perspectivas apuntadas arriba se encontraba la de efectuar intervenciones en los trabajos que estaban realizando otros investigadores del Centro de Birmingham. Se planteaban cómo su investigación feminista podía transformar las investigaciones y el conocimiento ya existentes, y llegaron a pensar que para ello tendrían que 'conquistar' todo el campo de los Estudios Culturales, que ya de por sí es multidisciplinar, y una vez hecho eso hacer una crítica feminista. Pero la alternativa que adoptaron finalmente fue la de concentrarse en lo que estimaron eran las principales áreas de investigación del Grupo de Estudios de la Mujer, arriesgándose a que sus preocupaciones quedaran dentro del campo específico del género. Es decir, los temas de la mujer quedaban relegados a ser sólo objeto de interés de quienes los reivindicaban: las mujeres. ${ }^{30} \mathrm{Su}$ trabajo intelectual se enfrentaba constantemente con la disparidad existente entre la sofisticación de los análisis de formación social en términos de clase y el poco trabajo que se había desarrollado sobre las estructuras de sexo y género. La necesidad de realizar investigaciones concretas e históricamente específicas desde una perspectiva feminista quedaba en 1978 como el aprendizaje más importante que había logrado el Grupo de Estudios de la Mujer en los últimos años de trabajo. ${ }^{31}$

En la conclusión al artículo de introducción, que las editoras admiten haber redactado con dificultad, afirman que la producción del libro se debe en muy buena parte a las muchas contradicciones que se han esforzado por reflejar en el mismo. Los diferentes puntos de vista tanto de las mujeres como de los hombres que se decidieron a escribirlo tienen que ver con las diferentes formas de entender tanto lo que es el 'feminismo' y el 'trabajo intelectual' como las prácticas políticas. Uno de los puntos que se seguían planteando, y que les llevaba a cuestionarse qué es exactamente el feminismo, es si los hombres pueden o no ser feministas; a eso había que añadirle la incertidumbre sobre si sus textos debían ir dirigidos principalmente a mujeres o a hombres, o si era posible dirigirse a ambos a la vez en los mismos términos. Reconocen haber intentado ocultar en buena parte esas diferencias y desacuerdos en el intento de hacer el relato de los orígenes del libro. ${ }^{32}$

En el fondo reconocen que la producción del libro fue un proceso de educación política e intelectual tanto para los que contribuyeron al mismo como para otros miembros del Centro. Afirman que la razón inicial por la que se embarcaron en el proyecto era fundamental: la ausencia continuada de una preocupación visible dentro del Centro 
${ }^{33}$ WOMEN'S STUDIES GROUP, 1978, p. 15.

${ }^{34}$ WOMEN'S STUDIES GROUP, 1978, p. 16.

${ }^{35}$ FRANKLIN, LURY y STACEY, 1991, p. ix.

de Estudios Culturales Contemporáneos por los temas feministas. En su opinión, uno de los resultados positivos del proceso fue conseguir que el feminismo fuera más aceptado dentro del Departamento; otro aspecto positivo fue la experiencia de politización en que se convirtió el trabajo editorial para los que compusieron el grupo. Concluyen retornando a lo que ven como tema central de su trabajo: "Una de las cosas que queremos de los Estudios de la Mujer es que contribuya a hacer un análisis feminista de 'cómo están las cosas' - crítica de discursos existentes, descubrimiento de nuevo material y nuevos cuestionamientos y desarrollo de una aproximación teórica a la subordinación de las mujeres bajo el capitalismo". ${ }^{33}$ Esa es la dirección hacia la que enfoca el libro, aunque acaban reconociendo que perciben de una manera diferente la naturaleza de sus contradicciones al tratar de obtener un reconocimiento que valide su trabajo intelectual feminista dentro de un contexto académico al tiempo que cuestionan los términos en que ese reconocimiento es concedido. Por esas diferencias políticas en cuanto a los logros de su trabajo afirman no haber podido llegar a un acuerdo sobre la conclusión. ${ }^{34}$

\subsection{Off-Centre: Feminism and Cultural Studies}

La segunda antología sobre mujeres y Estudios Culturales, Off-Centre: Feminism and Cultural Studies, fue editada en 1991 por Sarah Franklin, Celia Lury y Jackie Stacey. Las editoras afirman en el prefacio que el libro es producto tanto de una historia particular como de una tradición de trabajo también peculiar que se venía desarrollando en el campo de los estudios culturales en Birmingham. Presentan esta antología como una sucesora de Women Take Issue, vinculándola también al trabajo colectivo desarrollado en los subgrupos del Centro de Estudios Culturales Contemporáneos, que ya en 1991 había pasado a convertirse en Departamento de Estudios Culturales. ${ }^{35}$ Aunque reconocen que la trayectoria de los temas feministas en Birmingham desde la publicación de Women Take Issue no ha estado exenta de problemas, encuentran el lado positivo en el hecho de que el trabajo ha sido continuado, y afirman mantener la esperanza en que la publicación de esa segunda antología le haga justicia y perpetúe dicha trayectoria. Desde esta primera página, y en muchas ocasiones a lo largo del libro, aclaran que la relación entre el feminismo y los estudios culturales no es siempre una relación llevadera, tanto en lo que se refiere a puntos de vista de prácticas de trabajo como a puntos de vista intelectuales y políticos. Pero al mismo tiempo afirman que 
36 FRANKLIN, LURY y STACEY, 1991, p. ix.

${ }^{37}$ FRANKLIN, LURY y STACEY, 1991, p. ix-X.

${ }^{38}$ FRANKLIN, LURY y STACEY, 1991, p. 6.

${ }^{39}$ FRANKLIN, LURY y STACEY, 1991, p. 7. la antología fue concebida y producida con un fuerte compromiso de demostrar la utilidad de combinar esos distintos puntos de vista, así como de perfeccionarlos y redefinirlos continuamente. ${ }^{36}$

Esta antología surge concretamente en uno de los subgrupos del Centro, el Women Thesis Writers' Group, en el que algunas alumnas de postgrado feministas se reunían con otras mujeres afiliadas al Centro para intercambiar sus trabajos escritos, reflexionar sobre los mismos y debatir otras ideas más generales sobre el feminismo. Lo que según las editoras de Off-Centre produjo el impulso definitivo para publicar el libro fue la celebración del décimo aniversario de Women Take Issue, que les hizo plantearse la conveniencia de lanzarse a un proyecto que le sucediera y que documentara la contribución continuada de las feministas a los estudios culturales en Birmingham. En aquellos momentos de finales de los años ochenta ya se reconocía a muchos niveles el diálogo existente entre el feminismo y los estudios culturales, así como la importancia de la imbricación entre la teoría cultural y el feminismo. ${ }^{37}$

En opinión de las editoras de Off-Centre, Women Take Issue fue un ejemplo temprano del trabajo feminista que se estaba llevando a cabo dentro de los estudios culturales, con una metodología que utilizaba la teoría marxista al tiempo que intentaba transformarla. Al centrarse en cuestiones como la reproducción cultural y la producción, esa primera antología resaltó la necesidad de que los estudios culturales se acercaran a las dimensiones 'personales' de la cultura en el contexto político del análisis feminista. Las editoras de OffCentre destacan la importancia de ese libro al afirmar que a partir de su publicación el impacto del feminismo en los estudios culturales fue teniendo una relevancia que iba en aumento. Eso se pudo observar por ejemplo en cómo el interés inicial por temas como la ideología o la hegemonía fue transformándose en un mayor interés por la identidad y la subjetividad. Ellas atribuyen ese cambio no sólo a las intervenciones feministas, sino también a la influencia del psicoanálisis y del post estructuralismo. ${ }^{38}$ Otro tema de interés creciente en los estudios culturales gracias al feminismo es el de la sexualidad, aunque ahí las editoras de Off-Centre matizan que aunque en algunos casos se ha analizado la sexualidad y su relación con el género, la forma en que se han realizado los análisis sobre la sexualidad ha sido muy selectiva, sin integrar en muchas ocasiones los análisis feministas como el de la institución patriarcal de la heterosexualidad. Lo mismo ocurría, afirmaban las editoras, con los temas de gays y lesbianas, que en aquellos primeros años de la década de los noventa del siglo XX estaban comenzando muy lentamente a ser tomados en serio dentro de los estudios culturales. ${ }^{39}$ 
40 FRANKLIN, LURY y STACEY, 1991, p. 1.

${ }^{41}$ FRANKLIN, LURY Y STACEY, 1991, p. 1-2.
En el primero de los dos ensayos que forman parte de la Introducción a Off-Centre, titulado "Feminism and Cultural Studies: Pasts, Presents, Futures", las editoras - manejando el lenguaje propio de la época - afirman que el libro trata de formas de conocimiento, poder y política, aunando el feminismo y los estudios culturales en una variedad de contextos. Añaden que tanto el feminismo como los estudios culturales tienen historias complicadas y contradictorias, dentro y fuera de la academia; en cualquier caso, resaltan que no existe una historia única, lineal y unificada de ninguno de los dos campos, por lo que no se van a esforzar en contarla, sino más bien en resaltar tres de los aspectos que encuentras más relevantes, lo que consideran que son los temas clave en su desarrollo: los paralelismos existentes entre feminismo y estudios culturales, la falta de imbricación entre ambos y finalmente los tres tipos de imbricación que sí parecen existir, cuyos contenidos dan pie a la estructura final de la antología. ${ }^{40}$

En esa primera sección de la introducción, que indaga en los paralelismos entre los estudios de la mujer y los estudios culturales, afirman que ambas disciplinas tienen en común su fuerte compromiso con la política fuera de la academia, con unas agendas políticas cercanas al movimiento feminista en el primer caso y a la política de izquierdas en el segundo. Añaden que la base interdisciplinar que también comparten ha retado de una forma importante las fronteras académicas y las estructuras de poder, centrándose en el análisis de las formas de poder y la opresión y en las políticas de producción del conocimiento tanto dentro de la academia como en la sociedad. ${ }^{41}$ Además, también comparten el haber retado algunas de las convenciones existentes en la práctica académica, introduciendo el trabajo colectivo frente al individual, incluyendo a las/os alumnas/os en la construcción de los programas de estudio y abriendo espacios donde se conectan la experiencia personal y las cuestiones teóricas. Recordemos que el asunto de la experiencia personal era uno de los que el Centro de Estudios Culturales cuestionaba al grupo de estudios de la mujer en sus comienzos, tal y como expusieron las editoras de Women Take Issue. Sin embargo, a pesar de todos esos aspectos que tienen en común, las editoras de Off-Centre se paran a analizar cómo el desarrollo de los estudios de la mujer y de los estudios culturales no ha ido a la par. Se centran primero en el desarrollo del feminismo y los estudios de la mujer, para pasar posteriormente al de la teoría marxista, la política de izquierdas y los estudios culturales.

En el primero de los casos, afirman que los estudios de la mujer han ofrecido al feminismo una base institucional 
42 FRANKLIN, LURY y STACEY, 1991, p. 2.

${ }^{43}$ FRANKLIN, LURY y STACEY, 1991, p. 3. para la educación de adultos durante un período ya en 1991 de diez años, consiguiendo establecer un espacio dentro de las instituciones educativas desde el que se puede documentar, analizar y teorizar la posición de las mujeres en la sociedad. La existencia de muchos cursos de grado y de postgrado sobre estudios de la mujer, así como el hecho de que las editoriales más importantes incluyan los estudios de la mujer o de género en sus listas dan prueba de ello, junto con las múltiples publicaciones de editoriales feministas. $\mathrm{Si}$ en las primeras intervenciones que pudo realizar el feminismo en la academia, tal como quedó constatado en el análisis de Women Take Issue, tenían que hacer un esfuerzo por resaltar la ausencia de atención al género dentro de las teorías y debates existentes, los siguientes pasos fueron el reto a los conocimientos académicos y la introducción de nuevos temas en la academia. El hecho de que se introdujeran en las agendas académicas temas como la violencia masculina, la sexualidad y la reproducción dan una muestra de los logros de las feministas, en su convencimiento de que 'lo personal es político'. Estos temas, entre otros muchos, se convirtieron en objeto de estudio no sólo de los estudios de la mujer, sino de disciplinas como la sociología, la antropología, la historia o la literatura. ${ }^{42}$

Las feministas no se centraron sólo en documentar la opresión de las mujeres, sino que comenzaron a desarrollar teorías más generales para explicar el cómo y el por qué de la subordinación de las mujeres. Las editoras de Off-Centre dan algunos ejemplos ilustrativos de los desarrollos en este campo: algunas feministas ampliaron las teorías marxistas de la explotación de los trabajadores en el capitalismo observando la posición de las mujeres asalariadas, y otras las ampliaron para incluir la división sexual del trabajo doméstico. Algunas se alejaron de la idea de las relaciones de clase, localizando la base de la subordinación de las mujeres en el sistema patriarcal, que para ellas es un sistema de explotación relativamente diferente, e introdujeron marcos y conceptos de análisis completamente nuevos. Y otras feministas resaltaron la importancia de las relaciones sociales patriarcales dentro de un conjunto de desigualdades que se entrecruzan, como el racismo, el heterosexismo, el imperialismo o la división de clases. ${ }^{43}$ También se discutió dentro del feminismo la utilidad del término 'patriarcado' en la explicación de la opresión de las mujeres, en un intento de ser más específicas en su uso. El tema principal de ese debate es hasta qué punto la subordinación de las mujeres es universal, y el trabajo de muchas antropólogas e historiadoras ha sido especialmente significativo para demostrar que la desigualdad de las mujeres es producto de la colonización, el imperialismo y la acumulación de capital. 
${ }^{44}$ FRANKLIN, LURY y STACEY, 1991, p. 3-4.

${ }^{45}$ FRANKLIN, LURY y STACEY, 1991, p. 4.

${ }^{46}$ FRANKLIN, LURY y STACEY, 1991, p. 4.
Si las primeras activistas e intelectuales se esforzaron por destacar los aspectos comunes de la opresión para demostrar que la dominación masculina era sistemática y afectaba a todas las áreas de la vida de las mujeres, en el desarrollo de los estudios de la mujer el feminismo se tuvo que enfrentar, para entender la opresión de las mujeres, al tema de las diferencias existentes entre ellas. Esas diferencias pueden ser de identidad étnica, de nacionalidad, de clase o de sexualidad, y obligaron al feminismo a revisar sus propias teorías y conceptos, asumiendo los modelos limitados de la categoría 'mujer'. ${ }^{44}$ Como resultado de la revisión, el feminismo asumió finalmente la fuerza que le proporcionaba la diferencia y la diversidad. Las editoras de Off-Centre afirman al respecto: "El reto, tanto a nivel teórico como político, consiste en saber si las feministas pueden mantenerse juntas por lo que tienen en común en relación a las estructuras sociales patriarcales opresoras sin negar las diferencias muy reales que existen entre las mujeres y las especificidades que resultan en distintas formas de opresión". ${ }^{45}$

Las editoras de esta antología reconocen que ese cuestionamiento de la categoría 'mujer' dentro de la teoría feminista se produjo no sólo por los cambios que ocurrieron dentro del movimiento, sino también por la aparición de dos teorías críticas que tuvieron un gran impacto en el feminismo: el postestructuralismo y el postmodernismo. El escepticismo que desprendían ambas teorías en cuanto a la posibilidad de que existan identidades únicas hizo cuestionar al feminismo la posibilidad de que existiera la categoría 'mujer' como algo unificado y con un significado fijo y determinado. Concretamente, la teoría psicoanalítica introdujo la idea de ese subconsciente imprevisible e incontrolable que llevaba a cuestionar esa identidad coherente que previamente se había buscado. ${ }^{46}$

Mientras todo esto ocurría dentro del debate feminista, los estudios culturales se fueron adaptando a los cambios que también se producían dentro de la teoría marxista y de la política de izquierdas, ocupando un lugar prominente en el desarrollo de teorías de producción y de consumo cultural. Sin ser una disciplina monolítica, al igual que los estudios de la mujer, los estudios culturales ofrecieron un espacio alternativo dentro de la educación superior desde el que se podía retar a las disciplinas tradicionales, cuestionando el tipo de conocimiento que éstas producían, así como las relaciones de poder que se establecían en las prácticas educativas. En un intento de dejar atrás los límites del determinismo económico y del énfasis en los modos de producción del marxismo, los estudios culturales aportaron análisis en los que las dimensiones culturales del poder y de la desigualdad cobraban más importancia (como ejemplo pode- 
${ }^{47}$ FRANKLIN, LURY y STACEY, 1991, p. 5-7.

${ }^{48}$ FRANKLIN, LURY y STACEY, 1991, p. 7. mos pensar en la revisión del canon literario, que comenzó a incluir textos de cultura popular). El impacto de las teorías críticas de la escuela de Frankfurt, el postestructuralismo, el psicoanálisis y el postmodernismo también fue muy importante en los estudios culturales. La teoría postestucturalista del discurso, derivada de la obra de Foucault, cuestionó la relación existente entre conocimiento, poder y política, y la noción de discurso se convertía en una alternativa al concepto marxista de ideología. El sujeto era ahora entendido como un producto de varios discursos del conocimiento, que se desarrollaba a través de la construcción de categorías sociales como la locura, la disciplina o la sexualidad. A esa idea del sujeto había que añadirle la que proponía el psicoanálisis de Lacan, como mencionábamos antes, que señalaba la importancia del subconsciente en la formación de la identidad, lo cual explicaba la naturaleza fragmentada de la subjetividad, así como la dificultad de mantener identidades estables y unificadas. Las teorías sobre etnicidad e identidad nacional y los análisis sobre el racismo también fueron integrados dentro de los estudios culturales desde finales de la década de los setenta Y no debemos olvidar la influencia del feminismo en el desarrollo de los estudios culturales, de la que ya hemos hablado y seguiremos hablando. ${ }^{47}$

Lo que ya en 1991 tenían claro las editoras de OffCentre eran los puntos en los que convergían el feminismo y los estudios culturales, así como aquellos en los que divergían. A nivel teórico ambas disciplinas coincidían en su preocupación por analizar las formas y operaciones del poder y la desigualdad, tomando como parte integral de esas operaciones la producción del conocimiento. Ambas recurren a la teoría del discurso, el postestructuralismo, el psicoanálisis, la semiótica y la desconstrucción, haciendo una crítica de esas teorías al tiempo que utilizan aquello que refuerza las teorías que ya el feminismo y los estudios culturales manejaban acerca del poder y la resistencia. ${ }^{48}$ Las divergencias que existen entre ambas disciplinas son, en opinión de las editoras de esta antología, bastante considerables, y sugieren que el orden de prioridades es algo diferente entre feminismo y los estudios culturales. Aunque no niegan que el feminismo ha influido en los estudios culturales, afirman que esta influencia tiene sus límites, y esos límites son importantes por lo que revelan de la interacción dispar que existe entre ambos campos. Uno de los ejemplos que dan de esos límites es la falta de interés que muestran los estudios culturales por el desarrollo de las teorías feministas sobre las desigualdades de género, que demuestran que los estudios culturales siguen bastante desinformados sobre las teorías del patriarcado. Eso conduce a 
${ }^{49}$ FRANKLIN, LURY y STACEY, 1991, p. 8-9.

50 FRANKLIN, LURY y STACEY, 1991, p. 14.

${ }^{51}$ FRANKLIN, LURY y STACEY, 1991, p. 14.

52 FRANKLIN, LURY y STACEY, 1991, p. 15. que los estudios culturales no se centren en explicar temas como la sexualidad, la reproducción o la violencia; mientras continúan preocupados por los factores económicos, políticos e ideológicos de la desigualdad, ignoran lo que el feminismo les puede aportar en sus análisis, con su cuestionamiento y revisión de las teorías críticas existentes. ${ }^{49}$

Volviendo a centrarse en los estudios de la mujer, las editoras de Off-Centre se plantean la necesidad de clarificar qué se debe entender por análisis feminista de la cultura, de tal manera que se pueda disponer de una serie de términos que ayuden a hacer ese análisis centrándose en el poder patriarcal y dilucidando cómo enfrentarse al mismo. En aquellos primeros años de la década de los noventa del siglo XX estaban comenzando a hacerse esas preguntas, con el debate esencialista todavía en el ambiente. ${ }^{50}$ Lo que plantean como objetivo de la antología, al aunar el feminismo y los estudios culturales, es pues considerar la importancia que dentro de la teoría y la política feministas tienen las cuestiones sobre las dimensiones culturales de la desigualdad de género y del poder patriarcal. Ellas se esfuerzan por demostrar en esta introducción que existen dos maneras de explorar cuál es esa importancia: una es investigar el papel que juega la cultura en la reproducción de la desigualdad de género, y la otra es preguntarse de qué manera un análisis de género puede contribuir a comprender la cultura. Reconocen que el proyecto no puede ser único, dada la diversidad de análisis feministas existentes, y afirman que la antología no pretende representar un modelo definitivo o general. Eso se puede entender si observamos las tres secciones principales en que se divide la misma, que según las editoras atienden a los tres puntos que sí tienen en común el feminismo y los estudios culturales. ${ }^{51}$

La primera sección de Off-Centre, que es de Introducción, consta de dos ensayos, uno, del que estamos hablando aquí, que se dedica a analizar los pasados, presentes, y futuros del feminismo y los estudios culturales y otro que relaciona el Feminismo, el Marxismo y el Thatcherismo, entroncando el feminismo con los modelos de análisis de estudios culturales que se estaban aplicando en el momento en que se editó el libro. Las tres secciones principales, que dan cuerpo a la antología, se introducen con los siguientes epígrafes: "Representación e Identidad", "Ciencia y Tecnología" y "El Thatcherismo y la Cultura de la Empresa". En opinión de las editoras, estas subdivisiones reflejan el interés de los que contribuyeron en el libro, casi todos relacionados con el Centro de Estudios Culturales de Birmingham, pero también cada sección es significativa por lo que indica de los tres tipos de interacciones que existen entre el feminismo y los estudios culturales en diferentes tipos de análisis. ${ }^{52}$ 
${ }^{53}$ FRANKLIN, LURY y STACEY, 1991, p. 15.
Los cinco ensayos que aparecen bajo el epígrafe de "Representación e Identidad" contribuyen, según las editoras, a un tipo de análisis en el que ambas disciplinas han estado bien representadas, dado el interés que han compartido en la cultura popular y en el análisis de la representación y la identidad, con un giro reciente en aquel momento hacia el tema del consumo y la recepción cultural. ${ }^{53}$ El primero de ellos trata sobre la audiencia de los melodramas y el género, el segundo sobre las revistas populares de adolescentes y la cultura dominante, el tercero analiza el feminismo y el placer de lo popular, el cuarto conecta el género, la autobiografía y la institución de lo literario, y el quinto explora en la posibilidad de integrar perspectivas feministas y de estudios culturales en el estudio de la masculinidad de los jóvenes de la clase obrera.

Bajo el epígrafe de "Ciencia y Tecnología" encontramos una estructura peculiar. El primer ensayo relaciona la ciencia y la tecnología con el feminismo y los estudios culturales, y posteriormente encontramos un epígrafe que se refiere a la reciente iniciativa legislativa anti aborto que había surgido en Gran Bretaña en la década de los 80 del siglo $X X$, denominada Alton Bill. En realidad, se trata de la presentación de un proyecto que había llevado a cabo el Subgrupo de Ciencia y Tecnología del Centro de Birmingham desde 1986. Es ese subgrupo el que introduce pues los cuatro ensayos que siguen, y que indagan todos en el que entonces era el polémico tema del aborto. Así, el primero de los ensayos explora las políticas de reproducción de la época, el segundo la construcción legal del aborto, el tercero la construcción médico-científica del feto y el cuarto el papel de los medios de comunicación ante la Alton Bill. En la conclusión a esa sección el Subgrupo de Ciencia y Tecnología del Centro de Birmingham hace un resumen de todos los aspectos tratados, hablando de los pasados, presentes y futuros del feminismo y el aborto, y resaltando el papel cultural que juega la ciencia en un debate como el de la Alton Bill. Las editoras de la antología afirman en la introducción que el tema de la ciencia y la tecnología es uno en el que el feminismo y los estudios culturales no tienen muchas cosas en común, siendo el feminismo el que ha mostrado más interés en ese análisis.

El tercer epígrafe que da estructura a la antología, el de "El Thatcherismo y la Cultura de la Empresa", es, en opinión de sus editoras, un intento de introducir enfoques feministas en un área que era central en aquellos momentos en los debates de los estudios culturales. Las feministas argumentaban que se había concedido poca atención hasta entonces a las dimensiones de género del Thatcherismo y la cultura de la empresa, lo cual era un ejemplo claro de esa falta de interacción existente entre ambas disciplinas. Cinco 
son los ensayos que componen esa sección: el primero habla sobre las políticas de género del Thatcherismo, el segundo sobre las imágenes de éxito de las mujeres empresarias, el tercero analiza la novela $A$ Woman of Substance, que fue publicada el mismo año en que Margaret Thatcher ganó las elecciones, el cuarto trata de cómo redefinir las identidades culturales, y el quinto se refiere a otra polémica iniciativa del gobierno Thatcher, que promovió una iniciativa legislativa contra gays y lesbianas denominada 'Sección 28'.

Estas tres secciones, según las editoras, tratan de proporcionar ideas sobre cómo desarrollar un análisis cultural feminista, utilizando todo lo que hay de valioso dentro de los estudios culturales. Sin embargo, añaden, también se deben tener en cuenta las limitaciones de algunos de esos modelos de análisis. Finalmente, vuelven a afirmar cómo, a su vez, el análisis feminista puede servir como fuente y como estímulo para los estudios culturales, en ese proyecto compartido de cuestionar las convenciones de producción y distribución del conocimiento y de combinar el debate teórico con estrategias para provocar cambios.

\section{Reflexiones finales}

El proceso de elaboración de las dos antologías que hemos analizado refleja la variedad de cuestiones a las que tuvo que enfrentarse el feminismo para ser aceptado como herramienta de análisis en un campo aparentemente tan abierto como el de los Estudios Culturales. De los esfuerzos que hicieron las feministas para hacer notar la ausencia importante de los análisis de género en el trabajo de sus compañeros del Centro de Birmingham da buena cuenta la primera antología publicada, y la asunción de algunos temas y herramientas de análisis por parte de esos intelectuales, con un desarrollo no exactamente paralelo al del trabajo que estaban llevando a cabo sus compañeras, queda reflejada en la segunda antología. En cualquier caso, ambas publicaciones son un buen ejemplo no sólo de los logros de este grupo de mujeres - y algunos hombres - en el campo de los Estudios Culturales, sino también del talante con el que se enfrentaban a su trabajo, insistiendo constantemente en que el debate intelectual fuera continuo con el objetivo final de que tanto el Feminismo como los Estudios Culturales supieran aprovechar cuanto de útil hay en cada uno de ellos.

Antes de terminar debemos aclarar que ese proceso "interrumpido" por el feminismo al que nos referimos anteriormente y cuya mención venía entrecomillada por los editores de la antología Cultural Studies tiene una explicación precisa. Estos autores están citando a uno de 
${ }^{54}$ HALL, 1992, p. 282.

55 Además del verbo "interrupt", Hall utiliza el verbo "break in", que en inglés implica, entre otras acepciones, entrar en algún sitio a la fuerza, o interrumpir una conversación o actividad.

${ }^{56}$ HALL, 1992, p. 282.

57 "Take issue with" significa estar en desacuerdo.

${ }^{58}$ HALL, 1992, p. 282.

${ }^{59}$ HALL, 1992, p. 283. los participantes en la antología, nada más y nada menos que Stuart Hall, el que fuera director del Centro de Birmingham durante diez años. En su ensayo "Cultural Studies and Its Theoretical Legacies", en el que hace un repaso a la historia de la disciplina, Hall polemiza sobre la llegada del Feminismo a los Estudios Culturales, afirmando que "hubo al menos dos interrupciones en el trabajo del Centro de Estudios Culturales Contemporáneos: una provocada por el feminismo, y la otra por los temas de raza". ${ }^{4}$ Hall admite que la intervención feminista fue decisiva, rompedora y revolucionaria tanto a nivel teórico como práctico, y entre las aportaciones que introdujo en los Estudios Culturales destaca el haber planteado la cuestión de lo personal como político, el haber expandido la noción de poder al acercarla a cuestiones de género y sexualidad, el haber abierto el debate sobre subjetividad y sujeto y finalmente, el haber reabierto las puertas al psicoanálisis. A pesar de su reconocimiento a las aportaciones teóricas del Feminismo a los Estudios Culturales, y en un tono que puede interpretarse como paternalista e irónico Hall insiste "deliberadamente" en la metáfora del feminismo como un elemento de distorsión, que "irrumpió" 55 bruscamente en la disciplina, y llega a decir: "Como el ladrón en la noche, irrumpió; interrumpió, hizo un ruido impropio, se apoderó del tiempo, se cagó sobre la mesa de los estudios culturales". ${ }^{56}$ En ese punto de su ensayo, menciona la primera antología publicada por las mujeres del Centro, Women Take Issue, y haciendo referencia al título, afirma que éste puede entenderse en los dos sentidos que sugiere esa expresión: las mujeres "se hicieron cargo de la publicación ese año e iniciaron una pelea" dentro del Centro. ${ }^{57} \mathrm{Hall}$ critica la actitud de sus compañeras feministas quienes, según relata, se resistieron a aceptar las sugerencias de muchos de los miembros del Centro (él mismo reconoce que la mayor parte eran, por supuesto, hombres) de "importar" académicas feministas destacadas, a pesar de que "estábamos abriendo la puerta a los estudios feministas, comportándonos como hombres buenos y transformados". ${ }^{58}$ Fue en ese momento, insiste Hall en su tono irónico, cuando "descubrí realmente la imbricación entre género y poder". ${ }^{59}$

Como ya hemos visto al revisar las introducciones a las dos antologías que hemos analizado, y como se puede deducir de las palabras de Stuart Hall, la llegada del feminismo al Centro de Estudios Culturales Contemporáneos de Birmingham provocó turbulencias intelectuales, académicas y políticas. Pero también aportó un nuevo y muy estimulante flujo de ideas y perspectivas que han contribuido a ampliar el punto de mira de quienes se dedican a los Estudios Culturales. Prueba de ello son las numerosas antologías publicadas a partir de la década de los 90 del siglo XX, algunas 
${ }^{60}$ HARTLEY, 2003, p. 169.

más generalistas, pero que incluyen apartados o ensayos sobre sexo y género, y otras específicamente dedicadas a esos temas. Así, Grossberg y los demás editores de la antología Cultural Studies, que al hacer el repaso histórico de la disciplina en 1992 hacían mención a los comentarios de Stuart Hall sobre la "interrupción" provocada por el feminismo, ya incluían en su extenso libro un apartado sobre "género y sexualidad", en el que se presentaban doce ensayos del total de cuarenta que conformaban la totalidad del volumen. Simon During también incluyó un apartado sobre sexualidad en la antología que publicó en 1993 - y que fue revisada y reeditada en 1999 - con la contribución de teóricas como Teresa de Lauretis, Judith Butler o Eve Kosofsky Sedgwick. En 2001, Toby Miller editó A Companion to Cultural Studies, antología en la que no aparece una sección específicamente dedicada a temas de género, pero sí un ensayo de Melissa Deem titulado "The Scandalous Fall of Feminism and the 'First Black President'", en el que la autora analiza las reacciones al escándalo Clinton-Lewinsky y cuestiona los discursos críticos a la reacción del feminismo ante ese caso, relacionándolo además con cuestiones de raza. Como muestra de las antologías que relacionan específicamente temas de género con estudios culturales encontramos Feminist Cultural Studies, editado por Terry Lovell en 1995, y del mismo año Out in Culture: Gay, Lesbian and Queer Essays on Popular Culture, editado por Corey Creekmur y Alexander Doty. En 1997, Angela McRobbie editó Back to Reality? Social Experience and Cultural Studies, antología en la que sexo y género es casi omnipresente, y en la que exactamente la mitad de los participantes son mujeres. John Hartley, al referirse a esta antología de McRobbie afirma que, además del hecho de que el cincuenta por ciento de los ensayos fueran escritos por mujeres, sorprendentemente, "Ias contribuciones de los hombres también se mostraban alertas a los temas de feminización y sexualidad", lo cual hace de la publicación un texto innovador. ${ }^{60}$ Recién estrenado el siglo XXI, en el año 2000, Sue Thornham publicaba el libro Feminist Theory and Cultural Studies y Jacqueline Bobo editaría en 2001 Black Feminist Cultural Criticism, antología que relacionaba cuestiones de género y raza.

La actividad del Centro de Estudios Culturales Contemporáneos de Birmingham fue literalmente interrumpida cuando las autoridades académicas de su Universidad decidieron cerrarlo en el año 2002. En aquel momento, el Centro ya se había convertido en un referente histórico para la disciplina, y su influencia se había extendido a muchos lugares, sobre todo en el mundo anglosajón. Sin embargo, aunque el centro que viera nacer los Estudios Culturales haya dejado de existir, su legado es incuestionable, y a la 
${ }^{61}$ HARTLEY, 2003, p. 7.

${ }^{62}$ DEEM, 2006, p. 425. disciplina aún parece quedarle una larga vida por delante; precisamente en el libro A Short History of Cultural Studies, publicado por John Hartley en 2003, el autor afirmaba que aún existen lagunas dentro de los Estudios Culturales, asuntos pendientes que resolver. Uno de ellos sería su internacionalización más allá de lo que él denomina el "eje de la triple-A": el contexto anglo-americano-australiano. Hartley reconocía que la disciplina había comenzado a desarrollarse en lugares como China, Taiwán, Hong Kong, Singapur, Sudáfrica, América Latina, o el Sureste asiático, y esperaba que al afianzarse en ellos aparecieran campos de interés nuevos y estimulantes, así como voces diferentes dentro de los Estudios Culturales. ${ }^{61}$ Habrá que estar alerta pues a las "interrupciones" que lleguen desde todos esos y muchos otros lugares del planeta, que no podrán sino añadir diferentes perspectivas y formas de ver y hacer los Estudios Culturales. En cuanto a los estudios de género, y aunque actualmente pocos se atrevan a cuestionar su utilidad, también parece que queda aún mucho por hacer. El feminismo ya no se ve obligado a ser tan reivindicativo como en sus orígenes, pero aunque algunos crean que es algo del pasado, el mundo actual sigue necesitando reflexionar sobre las relaciones de género e identidad y su importancia para provocar cambios sociales: los estudios de la mujer y de género siguen siendo necesarios. Melissa Deem afirma en el ensayo que mencionamos antes que debemos dedicar especial atención a las historias populares sobre el feminismo, no tanto para desacreditarlas, sino porque la falta de historia feminista en la esfera pública limita las posibilidades de la política feminista contemporánea. ${ }^{62}$ Entendemos que sus palabras justifican el análisis que hemos llevado a cabo en este ensayo, ahondando en una parte de la historia del feminismo para descubrir que algunas luchas e "interrupciones" pueden dar frutos positivos para el futuro.

\section{Referencias bibliográficas}

BOBO, Jacqueline (ed.). Black Feminist Cultural Criticism (Keyworks in Cultural Studies). Malden, MA: Blackwell, 2001. CREEKMUR, Corey, and DOTY, Alexander (eds.). Out in Culture: Gay, Lesbian and Queer Essays on Popular Culture. Durham, NC: Duke University Press, 1995.

DEEM, Melissa. "The Scandalous Fall of Feminism and the 'First Black President'." In: MILLER, Toby (ed.). A Companion to Cultural Studies. Oxford: Blackwell, 2006. p. 407-429.

DURING, Simon (ed.). The Cultural Studies Reader. London: Routledge, 1993.

FALUDI, Susan. Backlash: The Undeclared War Against Women.London: Chatto and Windus, 1992. 
FRANKLIN, Sarah, LURY, Celia, and STACEY, Jackie (eds.). OffCentre: Feminism and Cultural Studies. London: Harper Collins Academic, 1991.

GROSSBERG, Lawrence, NELSON, Cary, and TREICHLER, Paula A. (eds.). Cultural Studies. New York: Routledge, 1992.

HALL, Stuart. "Cultural Studies and Its Theoretical Legacies." In: GROSSBERG, Lawrence, NELSON, Cary, and TREICHLER, Paula A. (eds.). Cultural Studies. New York: Routledge, 1992. p. 277-294.

HARTLEY, John. A Short History of Cultural Studies. London: Sage Publications, 2003.

HOGGART, Richard. The Uses of Literacy. Harmondsworth: Penguin, 1958.

LOVELL, Terry (ed.). Feminist Cultural Studies. London: Edward Elgar, 1995.

MAC AN GHAILL, Máirtín, and HAYWOOD, Chris. Gender, Culture and Society: Contemporary Femininities and Masculinities. New York: Palgrave Macmillan, 2007.

McROBBIE, Angela. "Post-Marxism and Cultural Studies: A Postscript." In: GROSSBERG, Lawrence, NELSON, Cary, and TREICHLER, Paula A. (eds.). Cultural Studies. New York: Routledge, 1992. p. 719-730.

McROBBIE, Angela (ed.). Back to Reality? Social Experience and Cultural Studies. Manchester: Manchester University Press, 1997.

MILLER, Toby (ed.). A Companion to Cultural Studies. Oxford: Blackwell, 2006[2001].

NELSON, Cary, TREICHLER, Paula A., and GROSSBERG, Lawrence. "Cultural Studies: An Introduction." In: GROSSBERG, Lawrence, NELSON, Cary, and TREICHLER, Paula A. (eds.). Cultural Studies. New York: Routledge, 1992. p. 1-22.

OAKLEY, Ann. Sex, Gender and Society. London: Temple Smith, 1972.

THORNHAM, Sue. Feminist Theory and Cultural Studies. Tester: Arnold, 2000.

WILLIAMS, Raymond. Culture and Society 1780-1950. London: The Hogarth Press, 1982 [1958].

WOMEN'S STUDIES GROUP (eds.). Women Take Issue: Aspects of Women's Subordination. London: Hutchinson, 1978.

[Recebido em julho de 2007 e aceito para publicação em setembro de 2008] 
Women Who 'Interrupt' Processes: The First Feminist Anthologies in Cultural Studies Abstract: The aim of this paper is to analyse the process of elaboration and production of the first two anthologies which were edited by women in the academic discipline known as Cultural Studies. Information about the role played by women in the development of that discipline has been taken from both publications. After a brief overview of the history of Cultural Studies, and of the contributions which it offered to the academic world, there will be a section analysing the birth of Women's Studies, and its relationship with Cultural Studies. Finally, I will focus on the analysis of the processes of publication of both anthologies, which were a result of the incorporation of feminism to the discipline. The analysis will endeavour to show how what some critics have called the feminist 'interruption' of the development of the process which Cultural Studies was undergoing at the end of the 70's in the $20^{\text {th }}$ century, was in fact an enormous contribution to the discipline. The inclusion of new subjects and concepts in the academic debate, as well as new tools of analysis, provide evidence of that contribution, despite the difficulties which feminist intellectuals had to face at the start.

Key Words: Feminism, Cultural Studies, Women's Studies, Anthologies. 